\title{
Singlet Oxygen Metabolism: From Genesis to Signaling
}

\author{
Vivek Dogra and Chanhong Kim * \\ Shanghai Center for Plant Stress Biology and Center of Excellence in Molecular Plant Sciences, Chinese Academy of \\ Sciences, Shanghai, China
}

Singlet oxygen $\left({ }^{1} \mathrm{O}_{2}\right)$ is an excited state of molecular oxygen with an electron spin shift in the molecular orbitals, which is extremely unstable and highly reactive. In plants, ${ }^{1} \mathrm{O}_{2}$ is primarily generated as a byproduct of photosynthesis in the photosystem II reaction center (PSII RC) and the light-harvesting antenna complex (LHC) in the grana core (GC). This occurs upon the absorption of light energy when the excited chlorophyll molecules in the PSII transfer the excess energy to molecular oxygen, thereby generating ${ }^{1} \mathrm{O}_{2}$. As a potent oxidant, ${ }^{1} \mathrm{O}_{2}$ promotes oxidative damage. However, at sub-lethal levels, it initiates chloroplast-to-nucleus retrograde signaling to contribute to plant stress responses, including acclimation and cell death. The thylakoid membranes comprise two spatially separated ${ }^{1} \mathrm{O}_{2}$ sensors: $\beta$-carotene localized in the PSII RC in the GC and the nuclear-

OPEN ACCESS

Edited by:

Chikahiro Miyake,

Kobe University, Japan

Reviewed by:

Thomas Roach,

University of Innsbruck, Austria

Jean-David Rochaix,

Université de Genève, Switzerland

*Correspondence:

Chanhong Kim

chanhongkim@sibs.ac.cn

Specialty section:

This article was submitted to

Plant Physiology,

a section of the journal

Frontiers in Plant Science

Received: 24 September 2019

Accepted: 21 November 2019

Published: 08 January 2020

Citation:

Dogra V and Kim C (2020) Singlet Oxygen Metabolism:

From Genesis to Signaling.

Front. Plant Sci. 10:1640.

doi: 10.3389/fp/s.2019.01640 encoded chloroplast protein EXECUTER1 (EX1) residing in the non-appressed grana margin (GM). Finding EX1 in the GM suggests the existence of an additional source of ${ }^{1} \mathrm{O}_{2}$ in the GM and the presence of two distinct ${ }^{1} \mathrm{O}_{2}$-signaling pathways. In this review, we mainly discuss the genesis and impact of ${ }^{1} \mathrm{O}_{2}$ in plant physiology.

Keywords: singlet oxygen $\left({ }^{1} \mathrm{O}_{2}\right)$, grana core (GC), grana margin (GM), photoinhibition, retrograde signaling, $\beta$-carotene, EXECUTER1 (EX1)

\section{SINGLET OXYGEN GENESIS IN PSII-LHC}

Singlet oxygen $\left({ }^{1} \mathrm{O}_{2}\right)$ is a peculiar reactive oxygen species (ROS), generated via energy transfer from excited chlorophyll to molecular oxygen during photosynthesis mainly at the photosystem II lightharvesting antenna complex (PSII-LHC) located in the appressed region, namely the grana core (GC) of the thylakoid membrane (Foote, 1968; Gollnick, 1968; Krieger-Liszkay, 2005; Triantaphylidès and Havaux, 2009). Upon absorption of light energy, chlorophyll in LHC attains a high energy but short-lived (few ns, $\sim 10^{-8} \mathrm{~s}$ ) singlet excited state $\left({ }^{1} \mathrm{Chl}{ }^{*}\right.$ ). A part of this absorbed light energy in ${ }^{1} \mathrm{Chl}^{*}$ is transferred to the reaction center chlorophyll P680 via resonance energy transfer to drive the photosynthetic electron transport chain (PETC). This process is referred to as photochemical quenching as it converts the harvested light energy into chemical energy (DemmigAdams and Adams, 2000; Muller et al., 2001). However, chlorophyll molecules absorb the light energy that exceeds the capacity of photochemical quenching. To avoid unwanted consequences, this excess of non-utilized light energy from ${ }^{1} \mathrm{Chl}^{*}$ is dissipated either as heat (called nonphotochemical quenching, NPQ) or as fluorescence (Demmig-Adams and Adams, 2000; Muller et al., 2001). In addition, the energy from ${ }^{1} \mathrm{Chl}^{*}$ also gets decayed via intersystem crossing (ISC, changing of spin in the molecular orbitals) which results in the formation of a lower energy triplet 
excited state of chlorophyll $\left({ }^{3} \mathrm{Chl}^{*}\right)$ with a comparatively longer half-life $\left(\sim 10^{-3} \mathrm{~s}\right)$ (Muller et al., 2001). The carotenoids present in the LHC, such as lutein and zeaxanthin, quench this ${ }^{3} \mathrm{Chl}^{\star}$ to prevent any unusual transfer of energy to other nearby molecules. However, if this ${ }^{3} \mathrm{Chl}^{\star}$ is not efficiently quenched, it reacts with molecular oxygen $\left({ }^{3} \mathrm{O}_{2}\right)$ released from the water-splitting reaction in the oxygen-evolving complex (OEC) and leads to the generation of ${ }^{1} \mathrm{O}_{2}$ (van Mieghem et al., 1995; Rinalducci et al., 2004; Santabarbara et al., 2007; Li et al., 2009) (Figure 1). This gain of energy results in an electron spin shift in the molecular orbitals, which makes ${ }^{1} \mathrm{O}_{2}$ very unstable and highly reactive.

In the PSII reaction center (RC), the P680 excites to a singlet state $\left({ }^{1} \mathrm{P} 680^{*}\right)$ once it absorbs light energy. ${ }^{1} \mathrm{P} 680^{*}$ then forms a radical pair with pheophytin (Pheo), ${ }^{1} \mathrm{P} 680^{+} \mathrm{Pheo}^{-}$, the first electron carrier intermediate, through a charge separation reaction (Vass et al., 1992; Adir et al., 2003; Hideg, 2004). This radical pair then transfers an electron to the primary electron acceptor quinone $\left(\mathrm{Q}_{\mathrm{A}}\right)$, leading to the formation of the long-lived second radical pair $\mathrm{P} 680^{+} \mathrm{Q}_{\mathrm{A}}{ }^{-}$(Krieger-Liszkay, 2005). After donating its electron to $\mathrm{Q}_{\mathrm{A}}$, the oxidized $\mathrm{P} 60^{+}$is re-reduced by extracting electrons from the water-splitting reaction in the OEC and returns to its ground state. However, if $\mathrm{Q}_{\mathrm{A}}$ is reduced due to the blockage of downstream electron transport (also called the closed state of PSII RC), it cannot accept any further electrons (Durrant et al., 1990). Such a condition allows the recombination of the primary radical pair $\left({ }^{3} \mathrm{P} 680^{+} \mathrm{Pheo}^{-}\right)$with P680 to a triplet state (Durrant et al., 1990; Krieger-Liszkay, 2005). The charge recombination reaction may also result in the formation of ${ }^{1} \mathrm{P} 680^{+} \mathrm{Pheo}^{-}$which consequently decays into ${ }^{3} \mathrm{P} 680^{+} \mathrm{Phe}^{-}$via ISC (Durrant et al., 1990; Krieger-Liszkay, 2005). The ${ }^{3} \mathrm{P} 680^{+} \mathrm{Pheo}^{-}$subsequently dissociates into Pheo and ${ }^{3} \mathrm{P} 680^{*}$ (Figure 1). Although PSII RC carries two molecules of $\beta$-carotene, their proximity to $\mathrm{P} 680$ is more than the Van der Waal's distance of $3.6 \AA$, which is essential to quench ${ }^{3} \mathrm{P} 680 *$. This allows ${ }^{3} \mathrm{P} 680^{*}$ to react with ${ }^{3} \mathrm{O}_{2}$ to generate ${ }^{1} \mathrm{O}_{2}$ (Durrant et al., 1990; van Mieghem et al., 1995; Hideg et al., 1998; Krieger-Liszkay, 2005; Santabarbara et al., 2007; Krieger-Liszkay et al., 2008) (Figure 1).

\section{${ }^{1} \mathrm{O}_{2}$ INCREASES UPON PHOTO INHIBITION}

Under long-lasting or adverse light-stress conditions, the rate of ${ }^{1} \mathrm{O}_{2}$ generation exceeds the scavenging capacity of chloroplasts and results in the increased photodamage of PSII and

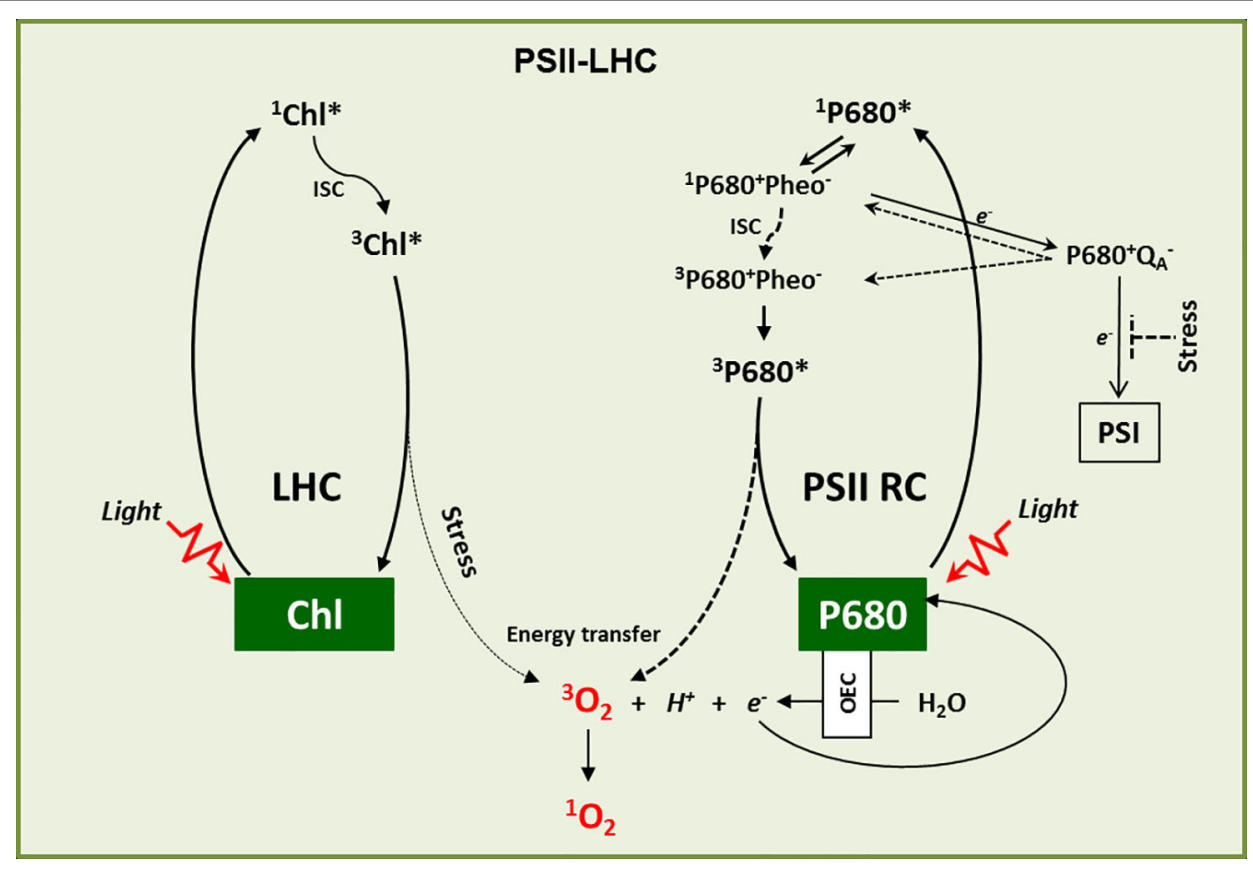

FIGURE 1 ${ }^{1} \mathrm{O}_{2}$ genesis. ${ }^{1} \mathrm{O}_{2}$ is primarily generated in the LHC and PSII RC. In the LHC, upon absorption of light energy, Chl is excited from the ground state to its excited singlet state $\left({ }^{1} \mathrm{Chl}{ }^{*}\right)$, which by intersystem crossing (ISC) turns into a comparatively long-lived excited triplet state $\left({ }^{3} \mathrm{Ch}{ }^{\star}\right) .{ }^{3} \mathrm{Chl} l^{*}$ is then quenched by carotenoids to come down to its ground state. However, under high light stress conditions it may react with ground state triplet oxygen $\left({ }^{3} \mathrm{O}_{2}\right)$, which leads to its excited singlet state $\left({ }^{1} \mathrm{O}_{2}\right)$. Similarly, P680 in the PSII RC attains excited singlet state $\left({ }^{1} \mathrm{P} 680^{*}\right)$ upon light absorption. The charge separation reaction between ${ }^{1} \mathrm{P} 680^{*}$ and Pheophytin (Pheo) results in the formation of the first radical pair ${ }^{1} \mathrm{P} 680^{+} \mathrm{Pheo}{ }^{-}$, followed by electron transfer to quinone $\mathrm{A}\left(\mathrm{Q}_{\mathrm{A}}\right)$ and the formation of the second radical pair ${ }^{1} \mathrm{P} 680^{+} \mathrm{Q}_{\mathrm{A}}^{-}$. After donating its electron to $\mathrm{Q}_{\mathrm{A}}$, the oxidized $\mathrm{P} 680^{+}$is re-reduced through the water-splitting reactions of the oxygen-evolving complex

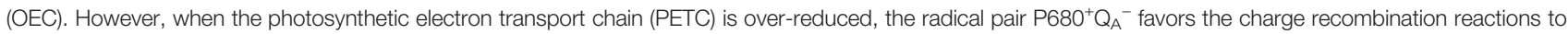
give rise either to ${ }^{3} \mathrm{P} 680^{+} \mathrm{Pheo}-$ through spin reversal or to ${ }^{1} \mathrm{P} 680^{+} \mathrm{Pheo}$. The recombined radical pair ${ }^{1} \mathrm{P}^{-} 80^{+} \mathrm{Pheo}{ }^{-}$then decays into ${ }^{3} \mathrm{P} 680^{+} \mathrm{Pheo}{ }^{-}$via intersystem crossing. P680 dissociates from ${ }^{3} \mathrm{P} 680^{+} \mathrm{Pheo}$ and subsequently forms ${ }^{3} \mathrm{P} 680^{\star}$, which reacts with ${ }^{3} \mathrm{O}_{2}$ to form ground state P680 and ${ }^{1} \mathrm{O}_{2}$. Under stress conditions such as $\mathrm{HL}$, cold, and drought, when the electron acceptor $\mathrm{Q}_{\mathrm{A}}$ is highly reduced, charge recombination reactions stimulate the accumulation of ${ }^{3} \mathrm{P} 680^{*}$ and the production of ${ }^{1} \mathrm{O}_{2}$. 
consequently decreased photosynthetic efficiency, a phenomenon called photoinhibition, (Hideg et al., 1998). Excess light enhances the rate of electron transfer in PSII, which can surpass the capacity of downstream electron acceptors in the photosynthetic electron transport chain, resulting in the over-reduction of $\mathrm{Q}_{\mathrm{A}}$ (Vass et al., 1992). The reduced $\mathrm{Q}_{\mathrm{A}}$ enhances the generation of ${ }^{1} \mathrm{O}_{2}$ via charge recombination reactions (Vass et al., 1992; Adir et al., 2003; Hideg, 2004) (Figure 1). Interestingly, not only the lightabsorbing chlorophyll molecules in PSII but also the uncoupled or weakly coupled ones of the antenna complex generate ${ }^{1} \mathrm{O}_{2}$, thereby eventually inducing photoinhibition (Santabarbara et al., 2002). Besides, inactivation of the oxygenevolving complex also leads to photoinhibition, referred to as donor-side photoinhibition (Keren et al., 1997). Plants grown under low light intensities can also exhibit photo-inactivation of PSII with an increased level of ${ }^{1} \mathrm{O}_{2}$, upon exposure to a flashlight (Szilard et al., 2005). In the presence of light, other stress factors (such as drought, cold, heat, salinity, and heavy metals) entail photoinhibition as a result of over-reduction of the photosynthetic electron transport chain (PETC) (Foyer and Noctor, 2005; Nishiyama et al., 2006; Takahashi and Murata, 2008; Li et al., 2009; Rochaix, 2011; Foyer et al., 2012; Nishiyama and Murata, 2014). The combination of HL with low temperature leads to photoinhibition as the low temperature slows down the PSII repair process (Baker, 1996). Treatments of plants with various herbicides also result in photoinhibition (Metz et al., 1986; Fufezan et al., 2002). The herbicide diuron (DCMU), e.g., blocks the electron transfer between $\mathrm{Q}_{\mathrm{A}}$ and $\mathrm{Q}_{\mathrm{B}}$ of PSII causing photoinhibition via ${ }^{1} \mathrm{O}_{2}$ (Metz et al., 1986).

\section{PSII DAMAGE}

Being a strong oxidant, ${ }^{1} \mathrm{O}_{2}$ induces irreversible photo-oxidative damage to the nearby biomolecules such as proteins, carotenoids, and lipids (Ravanat et al., 2000; Apel and Hirt, 2004; Davies, 2004; Watabe et al., 2007). Prime targets for ${ }^{1} \mathrm{O}_{2}$-driven chemical reactions are double bonds, e.g., in aromatic amino acids of proteins, polyunsaturated fatty acids (PUFA) in lipids and guanine bases in DNA, and thiol groups (Buettner, 1993). Besides, scavengers containing alternate double bonds or thiol groups, such as $\beta$-carotene, ascorbate, tocopherol, and glutathione, can also undergo oxidations upon a ${ }^{1} \mathrm{O}_{2}$ burst. Among these biomolecules, oxidation of lipids by ${ }^{1} \mathrm{O}_{2}$ primarily leads to a non-enzymatic peroxidation of PUFA, a hallmark of photo-oxidative damage (Mueller et al., 2006; Przybyla et al., 2008). Likewise, those amino acids containing side chains with alternate double bonds such as cysteine, histidine, methionine, tryptophan, tyrosine, and phenylalanine, all undergo oxidation by ROS (Michaeli and Feitelson, 1994). Tryptophan and its derivatives quench most of the ${ }^{1} \mathrm{O}_{2}$, followed by histidine, cysteine, methionine, tyrosine, and phenylalanine (Michaeli and Feitelson, 1994; Davies, 2004).

To alleviate photodamage, ${ }^{1} \mathrm{O}_{2}$ needs to be quenched by some molecular components in PSII either by energy transfer or through oxidative modifications (Foote and Denny, 1968; Gorman and Rodgers, 1992; Krieger-Liszkay and Trebst, 2006). Carotenoids, such as lutein and zeaxanthin residing in the close vicinity to $\mathrm{Chl}$ in LHC (less than the van der Waals distance of $3.6 \AA$ ), directly quench the excited ${ }^{3} \mathrm{Chl}^{\star}$ and ${ }^{1} \mathrm{O}_{2}$ (Gorman and Rodgers, 1992; Telfer et al., 1994; Telfer, 2002; Krieger-Liszkay and Trebst, 2006). This physical quenching of ${ }^{3} \mathrm{Chl}^{\star} /{ }^{1} \mathrm{O}_{2}$ excites the carotenoids to a higher energy triplet state $\left({ }^{3} \mathrm{Car}^{\star}\right)$, which then undergoes a decay via ISC, triplet-triplet annihilation, or ground-state quenching (Edge and Truscott, 1999; Burke et al., 2000). In contrast to the carotenoids in LHC, the $\beta$-carotene molecules present in the PSII RC are situated far from ${ }^{3} \mathrm{P} 680^{*}$ which prevents their direct quenching (Telfer et al., 1994). However, the distance between $\beta$-carotene and the ${ }^{1} \mathrm{O}_{2}$ generated in PSII RC is close enough for chemical quenching, leading to the oxidative modification of $\beta$-carotene (Foote and Denny, 1968; Krieger-Liszkay, 2005; Ramel et al., 2012a). Under light-stress conditions, a certain portion of ${ }^{1} \mathrm{O}_{2}$ evades the ${ }^{1} \mathrm{O}_{2}$ quenchers in PSII and diffuses into the thylakoid membrane, where it leads to lipid peroxidation. As a preventive measure, both tocopherol (Kruk et al., 2005) and PQ (Kruk and Trebst, 2008; Yadav et al., 2010), present in the thylakoid membranes, can detoxify ${ }^{1} \mathrm{O}_{2}$. In the stroma, ascorbate can also scavenge ${ }^{1} \mathrm{O}_{2}$ if it is released from the thylakoid membranes (Bisby et al., 1999).

Despite the efficient quenching by $\beta$-carotene, some amount of ${ }^{1} \mathrm{O}_{2}$ diffuses within the PSII RC leading to the irreversible modification of PSII RC proteins, especially D1 (Telfer, 2002; Vass and Cser, 2009). The irreversible modification hinders the electron transfer function of D1 and subsequently impairs the PSII activity (Aro et al., 1993) (Figure 2). The damaged PSII undergoes a repair process in the non-appressed grana called grana margin (GM) (Aro et al., 1993). The PSII repair involves the monomerization of the PSII dimer, followed by the migration of the PSII monomer from the GC to the GM, disassembly, degradation, and de novo synthesis of $\mathrm{D} 1$, insertion of the newly synthesized D1 protein into the thylakoid membrane concomitantly with the assembly of other components of PSII, migration of the PSII monomer to the grana core, and finally dimerization (Aro et al., 1993; Hakala et al., 2005). The GMlocalized membrane-bound hexameric FtsH metalloprotease plays a crucial role in PSII proteostasis by degrading damaged D1 proteins (Kato et al., 2009; Malnoë et al., 2014). Since D1 binds chlorophyll in the PSII, chlorophyll molecules probably become unbound during disassembly allowing the efficient degradation of D1. Consistently, during the de novo synthesis of the D1 protein, the nascent polypeptide chain is directly inserted into the D1-depleted PSII along with recycled or newly synthesized chlorophyll molecules. Collectively, the ${ }^{1} \mathrm{O}_{2}$ driven oxidative modification of D1 seems to underline its turnover (Aro et al., 1993; Hakala et al., 2005; Kato et al., 2009; Malnoë et al., 2014). Besides D1, the D2 protein of the PSII RC also exhibits a decline upon a ${ }^{1} \mathrm{O}_{2}$ burst, indicating probable photodamage of D2 by ${ }^{1} \mathrm{O}_{2}$ (Koivuniemi et al., 1995; Jansen et al., 1999; Edelman and Mattoo, 2008). In accordance, recent studies have demonstrated that the oxidative modification is not limited to D1, but rather all PSII RC proteins including D2, CP43, and 


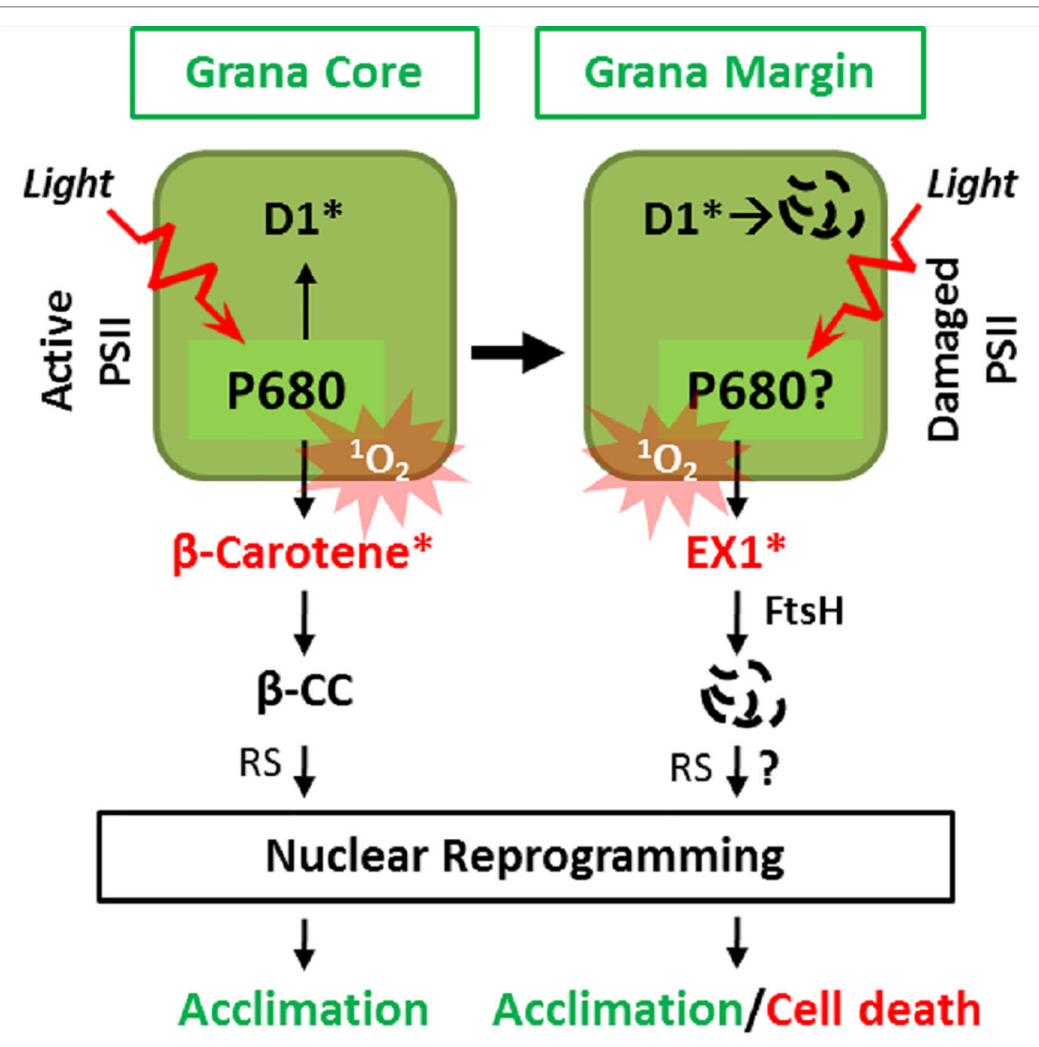

FIGURE 2 | Two spatially separated ${ }^{1} \mathrm{O}_{2}$ sensors and cognate retrograde signaling pathways. ${ }^{1} \mathrm{O}_{2}$ generated in the GC by the excited triplet state of P680 damages PSII RC, facilitating its repair in the GM. Under light stress conditions, the enhanced levels of ${ }^{1} \mathrm{O}_{2}$ result in the accumulation of $\beta$-cyclocitral ( $\beta$-CC), a volatile oxidative product of $\beta$-carotene, which mediates retrograde signaling to activate genes involved in detoxification, photoprotection, and acclimation. In the GM, the unbound free chlorophyll molecules released during disassembly/reassembly of PSIl or by de novo synthesis may generate ${ }^{1} \mathrm{O}_{2}$. The EX1 protein residing in the GM then senses the ${ }^{1} \mathrm{O}_{2}$ via its SOS domain and initiates ${ }^{1} \mathrm{O}_{2}$ signaling through the coordination of the $\mathrm{FtsH}$ protease. The EX1 proteolysis by Fts $\mathrm{H}$ appears to be essential for inducing changes in nuclear gene expression priming acclimation or cell death. The genuine signaling molecule(s) and the downstream signaling components involved in EX1-mediated signaling remain to be elucidated. *Denotes oxidized state.

CP47 get oxidized by ${ }^{1} \mathrm{O}_{2}$ (Dreaden Kasson et al., 2012; Dogra et al., 2019a; Dogra et al., 2019b; Duan et al., 2019). Though these oxidative modifications might be linked with the turnover, the precise relevance of these modifications in PSII proteins needs to be investigated.

\section{$\beta$-CAROTENE ALSO ACT AS A ${ }^{1} \mathrm{O}_{2}$ SENSOR IN THE GC TO INITIATE RS}

The primary function of $B$-carotene residing in the PSII RC is to scavenge ${ }^{1} \mathrm{O}_{2}$ to prevent PSII damage (Foote and Denny, 1968; Ramel et al., 2012b). This scavenging, however, leads to its nonenzymatic oxidative modification into aldehydes and endoperoxides (Foote and Denny, 1968; Ramel et al., 2012b). Under normal light conditions, the ${ }^{1} \mathrm{O}_{2}$-specific endo-peroxides of $\beta$ carotene such as $B$-cyclocitral ( $B-C C)$, Dihydroactinidiolide $(\mathrm{dh} A)$, and $\beta$-ionone are only detectable at negligible levels. However, under high light (HL), these oxidation products accumulate to significant levels (Ramel et al., 2012b). These endo-peroxides accumulate in proportion to the extent of PSII photoinhibition, which supports the notion that the PSII RC is the primary site of ${ }^{1} \mathrm{O}_{2}$ generation under excess light conditions (Ramel et al., 2012a). Interestingly, these endo-peroxides of $\beta$ carotene are highly reactive, volatile, and electrophilic compounds, thus referred to as reactive electrophile species (RES) (Ramel et al., 2012b). Recent studies in Arabidopsis wild-type and chlorina 1 (ch1) mutant plants revealed that $B$ $\mathrm{CC}$ and to some extent $\mathrm{dHA}$ act as ${ }^{1} \mathrm{O}_{2}$-signaling molecules (Ramel et al., 2012b; Ramel et al., 2013; Shumbe et al., 2014). Exogenous application of these RES compounds activates a plant acclimation response which mitigates the HL-induced photooxidative damages including lipid peroxidation. Pretreatment with $B-C C$ induces the expression of genes involved in photoprotection to prevent lipid peroxidation, leaf bleaching, and to maintain the photochemical activity upon subsequent exposure to HL (Ramel et al., 2012b). ß-CC induces a specific subset of genes, referred to as ${ }^{1} \mathrm{O}_{2}$-responsive genes (SORGs), which are quite distinct from those induced by $\mathrm{H}_{2} \mathrm{O}_{2}$ (Ramel et al., 2012b) (Figure 2). As compared to $ß-\mathrm{CC}$, dhA appears to induce a small subset of these SORGs (Shumbe et al., 2014), indicating that it is not a significant contributor in B-carotene-mediated RS.

The $\beta$-CC, being volatile, probably reaches the cytosol and/or the nucleus where it induces SORGs via some signaling 
components. An earlier genetic screen in the unicellular green alga Chlamydomonas reinhardtii has unveiled the small zinc finger protein Methylene Blue Sensitivity 1 (MBS1), localized both in the cytosol and the nucleus, as a probable downstream component of $\mathrm{B}$-CC-mediated ${ }^{1} \mathrm{O}_{2}$ signaling (Shao et al., 2013). Consistently, Arabidopsis mbs 1 mutant plants are not able to acclimate after pretreatment with $\beta$-CC to the lethal dose of HL stress (Shumbe et al., 2017). It was also shown that the MBS1 protein was required for the expression of a subset of $\beta$-CCinduced SORGs implicated in photo-acclimation (Shumbe et al., 2017). However, the precise mechanism of how MBS1 drives the gene expression remains unclear. A recent study reported that $\beta$ CC activates the TGAII/scarecrow like-14 (SCL14) transcription factors to induce detoxification-related genes required for the acclimation towards HL stress in Arabidopsis (D'Alessandro et al., 2018). Interestingly, the $\beta$-CC-mediated activation of TGAII/SCL14 TFs and downstream gene expression is independent of MBS1 (D’Alessandro et al., 2018), which suggests the existence of multiple components involved in this retrograde signaling operating in a spatio-temporal manner. Collectively, these observations conclude that the ${ }^{1} \mathrm{O}_{2}$ quencher $\beta$-carotene also act as a ${ }^{1} \mathrm{O}_{2}$ sensor in the PSII RC in the GC (Figure 2).

\section{THE GRANA MARGIN-ASSOCIATED ${ }^{1} \mathrm{O}_{2}$ SENSOR EXECUTER1}

Klaus Apel and his co-workers first demonstrated the signaling role of ${ }^{1} \mathrm{O}_{2}$ by utilizing the Arabidopsis fluorescent (flu) mutant (Meskauskiene et al., 2001). The flu mutant plants conditionally generate ${ }^{1} \mathrm{O}_{2}$ in chloroplasts upon a dark-to-light shift (Meskauskiene et al., 2001). In the dark, the FLU protein negatively regulates the accumulation of protochlorophyllide (Pchlide), a precursor of chlorophyll. Therefore, $f l u$ mutant plants initially grown under continuous light (permissive) conditions overaccumulate free Pchlide (non-protein-bound form) in the dark, which upon re-illumination acts as a potent photosensitizer (like ${ }^{3} \mathrm{Chl}^{\star}$ ), leading to the ${ }^{1} \mathrm{O}_{2}$ generation (Meskauskiene et al., 2001). This intriguing characteristic of the $f l u$ mutant enabled the discovery that ${ }^{1} \mathrm{O}_{2}$ rapidly induces nuclear gene expression changes, which precede cell death in seedlings and growth inhibition in mature plants (Meskauskiene et al., 2001; op den Camp et al., 2003). Hence, the flu mutant is now used as a bio-tool for investigating the ${ }^{1} \mathrm{O}_{2}$-mediated signaling and the mechanisms of chloroplast-mediated stress responses including cell death and growth inhibition (Meskauskiene et al., 2001; op den Camp et al., 2003; Wagner et al., 2004; Lee et al., 2007). Using this biotool, the genetic basis of ${ }^{1} \mathrm{O}_{2}$-mediated signaling has been illustrated: the nuclearencoded chloroplast protein EXECUTER 1 (EX1) mediates ${ }^{1} \mathrm{O}_{2}$-triggered nuclear gene expression changes, cell death, and growth inhibition (Wagner et al., 2004; Kim et al., 2012). Loss of EX1 significantly abolishes the ${ }^{1} \mathrm{O}_{2}$-induced stress responses in the flu mutant plants (Wagner et al., 2004; Lee et al., 2007). Also, EXECUTER2 (EX2), a close homolog of EX1, participates in the
EX1-mediated ${ }^{1} \mathrm{O}_{2}$ signaling as a putative modulator (Lee et al., 2007). Loss of function of both EX1 and EX2 almost completely abrogates the ${ }^{1} \mathrm{O}_{2}$-triggered stress responses in the $f l u$ mutant upon a dark-to-light shift (Lee et al., 2007) as well as in wild-type plants exposed to moderate light stress (Kim et al., 2012). Besides activating cell death, EX1 and EX2 are also involved in local and systemic gene expression changes leading to acclimation toward HL stress (Carmody et al., 2016). Interestingly, the EX1mediated signaling was found to be distinct and independent of the one mediated by $ß$-carotene (Ramel et al., 2013). This finding raises an important question regarding the reason for the existence of two independent ${ }^{1} \mathrm{O}_{2}$-signaling pathways.

Recent studies aiming to understand the mechanism of EX1mediated ${ }^{1} \mathrm{O}_{2}$ signaling have provided the first hint for understanding these two signaling systems. It appears that EX1 mostly localizes in the GMs. This result indicates that EX1 resides away from the active PSII RC in the GC, the primary site of ${ }^{1} \mathrm{O}_{2}$ generation. In the GMs, EX1 associates with PSII RC proteins (undergoing repair) and the PSII repair machinery (Figure 2; Wang et al., 2016). The nearly exclusive localization of EX1 in the GM not only resolves the vagueness of the presence of two independent ${ }^{1} \mathrm{O}_{2}$-triggered retrograde signaling pathways but also suggests the presence of an additional site of ${ }^{1} \mathrm{O}_{2}$ generation (Wang et al., 2016; Dogra et al., 2018; Foyer, 2018) (Figure 2). The idea regarding the alternative site of ${ }^{1} \mathrm{O}_{2}$ generation (i.e., GM) is in line with an earlier study showing that ${ }^{1} \mathrm{O}_{2}$ may also compromise the de novo synthesis of $\mathrm{D} 1$, which takes place at the GM, by directly targeting the PSII repair machinery as observed for the chloroplast elongation factor $G$ (CpEF-G) in Synechocystis sp. strain PCC6803 (Nishiyama et al., 2004). It is noteworthy that the oxidation of CpEF-G by ${ }^{1} \mathrm{O}_{2}$ in higher plants has not been reported to date.

Nevertheless, given the very short half-life ( $200 \mathrm{~ns}$ ) (Gorman and Rodgers, 1992) and imminent reactivity (Krieger-Liszkay, 2005), it is almost impossible that ${ }^{1} \mathrm{O}_{2}$ generated at PSII in the GC travels to the GM to oxidize the PSII repair machinery. Therefore, it is likely that the nonappressed thylakoid region may also generate ${ }^{1} \mathrm{O}_{2}$, perhaps during the PSII repair (Dogra et al., 2018). Another explanation might be that other reactive species with a more extended lifespan move from the GC to the GM to oxidize the PSII repair machinery. Although it remains to be elucidated, one may suppose that perturbations in the PSII repair may lead to the release of ${ }^{1} \mathrm{O}_{2}$ by tetrapyrrole molecules required for PSII reassembly. In fact, it was shown that EX1 also interacts with enzymes involved in chlorophyll biosynthesis (Wang et al., 2016).

\section{OXIDATIVE MODIFICATION OF EXECUTER1 IS ESSENTIAL TO MEDIATE ${ }^{1} \mathrm{O}_{2}$ SIGNALING}

Aiming to understand how EX1 mediates ${ }^{1} \mathrm{O}_{2}$ signaling, Wang et al. (2016) realized that EX1 undergoes degradation upon ${ }^{1} \mathrm{O}_{2}$ burst. This observation indicated that EX1 might undergo a post- 
translational modification via ${ }^{1} \mathrm{O}_{2}$, and its associated protease may coordinate ${ }^{1} \mathrm{O}_{2}$ signaling. Accordingly, EX1 was found to associate with the FtsH protease in the GM (Wang et al., 2016). Given that the FtsH protease complex is involved in PSII repair (Kato and Sakamoto, 2009) and that EX1 is associated with PSII proteins in the GM, EX1 might also affect PSII repair. However, neither the presence nor absence of EX1 did modulate the PSII repair (Wang et al., 2016). Nonetheless, a resulting reverse genetic approach revealed that EX1 proteins undergo FtsHdependent proteolysis, which turned out to be an essential step in initiating ${ }^{1} \mathrm{O}_{2}$ signaling (Figure 2). The loss of $\mathrm{FtsH} 2$, the major subunit of the FtsH protease, substantially compromises ${ }^{1} \mathrm{O}_{2}$ signaling in the $\mathrm{flu}$ mutant (Wang et al., 2016; Dogra et al., 2017; Dogra et al., 2019b) (Figure 2). Based on these observations, it was postulated that $\mathrm{FtsH}$ might recognize EX1 as a substrate probably upon its oxidation or conformational changes in response to ${ }^{1} \mathrm{O}_{2}$. Consistently, it was revealed that EX1 undergoes an oxidative post-translational modification (Oxi-PTM) at a specific tryptophan residue (Trp643) located in the domain of unknown function 3506 (DUF3506) upon exposure to ${ }^{1} \mathrm{O}_{2}$. This modification is indispensable for its degradation and the subsequent activation of RS. As Trp643 is present in the DUF3506 and this domain is vital for degradation, it is now dubbed as singlet oxygen senor (SOS) domain, and EX1 protein is designated as a ${ }^{1} \mathrm{O}_{2}$ sensor.

The EX1 proteolysis via the FtsH protease may release a yet unknown signaling molecule. A small EX1 proteolytic peptide per se may activate the ${ }^{1} \mathrm{O}_{2}$-triggered signaling cascade (Figure 2). Considering that EX2 also possess DUF3506, it is very likely that it might also undergo oxidative modification and the subsequent degradation. Further research addressing the possible release of a small peptide or signaling molecule correlated with EX1 degradation and the role of EX2 in EX1mediated signaling would provide mechanistic insights into this retrograde signaling.

\section{THYLAKOID LIPIDS CAN ALSO ACTIVATE ${ }^{1} \mathrm{O}_{2}$ SIGNALING VIA THEIR OXIDATIVE PRODUCTS}

Besides proteins and carotenoids in PSII, ${ }^{1} \mathrm{O}_{2}$ also targets thylakoid lipids. Oxidation of the PUFAs in the lipids results in the accumulation of oxidized lipid products, also called oxylipins, in the thylakoid membrane. Many of these oxylipins are electrophilic due to their $\alpha, \beta$-unsaturated carbonyl groups allowing them to react with electron-rich atoms in biological molecules. These lipid-derived RES include 12-oxo-phytodienoic acid (OPDA), phytoprostanes, aldehydes, and ketones (Imbusch and Mueller, 2000; Gobel et al., 2002; Mano, 2012). Some of these RES can alter the expression of nuclear genes to activate stress responses, including detoxification, defense, and cell death (Weber et al., 2004; Sattler et al., 2006; Mueller et al., 2008; Farmer and Mueller, 2013). The RES-driven nuclear gene expression changes overlap significantly with those induced by $\beta$-CC-mediated RS in Arabidopsis.
In green alga Chlamydomonas reinhardtii, pretreatment with a sub-lethal dose of ${ }^{1} \mathrm{O}_{2}$ induced rapid nuclear gene expression changes, conferring acclimation towards a subsequent challenge with a lethal dose of ${ }^{1} \mathrm{O}_{2}$ (Ledford et al., 2007). This pre-acclimation resulted in the significant upregulation of detoxification-related genes, such as Glutathione Peroxidase (GPX5/GPXH) and a Glutathione-STransferase (GSTS1), to sustain photo-oxidative stress (Ledford et al., 2007). The set of genes induced were similar to those induced by $\beta$-CC mediated signaling. However, the levels of $\beta$-CC were almost unchanged, whereas the lipidderived $\alpha, \beta$-unsaturated aldehydes, including 2-propenal (also called acrolein), hexenal, and malonaldehyde (MDA) were elevated in response to HL in Chlamydomonas (Roach et al., 2017), suggesting possible participation of these lipid-derived RES in this signaling. Notably, these lipid-derived RES tend to accumulate in response to ${ }^{1} \mathrm{O}_{2}$ stress not only in Chlamydomonas but also in plant leaves (Mano et al., 2010). Among these RES, acrolein comparatively shows higher accumulation. Although acrolein imposes toxicity to the plants by directly damaging photosynthetic apparatus (Mano et al., 2009), its exogenous treatment at comparatively lower levels can induce the expression of RES-responsive detoxification genes, including GST1 (Roach et al., 2017; Roach et al., 2018). Recent findings show that carotenederived RES $\beta$-CC activates SCL14/TGAII and NAC TFs to activate downstream detoxification system in Arabidopsis (D'Alessandro et al., 2018), on the other hand, lipid-derived RES activate Singlet Oxygen Resistant 1 (SOR1), a bZIP10 transcription factor, to drive the expression of acclimation related genes in Chlamydomonas (Fischer et al., 2012). According to these recent findings, the role of the lipidderived RES is apparent in ${ }^{1} \mathrm{O}_{2}$ signaling, though the precise mechanism of their perception and activation of downstream signaling remains to be elucidated. Because many RES molecules, both carotenoid- and lipid-derived, are generated simultaneously upon exposure to light stress, linking a RES to a particular RS pathway remains mostly unexplored.

\section{CONCLUDING REMARK}

The ${ }^{1} \mathrm{O}_{2}$ is generated as a byproduct of photosynthesis. In addition to its well-known damaging effect, at sub-lethal levels, ${ }^{1} \mathrm{O}_{2}$ seems to trigger distinct retrograde signaling pathways via oxidative modification of carotenoids, proteins, and lipids to activate multiple stress responses (Ledford et al., 2007; Kim et al., 2008; Triantaphylides and Havaux, 2009; Kim and Apel, 2013; Zhang et al., 2014; Zhu, 2016; Dogra et al., 2018). Recent studies have established that the thylakoid membranes are equipped with distinct ${ }^{1} \mathrm{O}_{2}$ sensors: $\beta$ carotene located in the GC and EX1 proteins localized in the GM, both of which undergo oxidative modifications to mediate independent ${ }^{1} \mathrm{O}_{2}$-signaling pathways (Ramel et al., 2012b; Dogra et al., 2019b). These studies also suggested that, besides the active PSII in the GC, the GM may also generate ${ }^{1} \mathrm{O}_{2}$, 
perhaps during PSII repair (Wang et al., 2016; Dogra et al., 2018; Foyer, 2018). While the source of ${ }^{1} \mathrm{O}_{2}$ generation in the GC is well understood, it is unclear how the GM generates ${ }^{1} \mathrm{O}_{2}$. In these regards, further investigation on ${ }^{1} \mathrm{O}_{2}$ sensors would provide insights into the source of EX1 oxidation in the GM and the reason for the presence of two distinct ${ }^{1} \mathrm{O}_{2}$ signaling pathways. Although the role of thylakoids lipids is emerging as putative sensors of ${ }^{1} \mathrm{O}_{2}$, the precise mechanism by which the lipid peroxidation-mediated signaling activates the retrograde signaling need to be investigated.

\section{AUTHOR CONTRIBUTIONS}

VD and CK wrote the manuscript.

\section{REFERENCES}

Adir, N., Zer, H., Shochat, S., and Ohad, I. (2003). Photoinhibition - a historical perspective. Photosynth. Res. 76, 343-370. doi: 10.1023/A:1024969518145

Apel, K., and Hirt, H. (2004). Reactive oxygen species: metabolism, oxidative stress, and signal transduction. Annu. Rev. Plant Biol. 55, 373-399. doi: 10.1146/annurev.arplant.55.031903.141701

Aro, E. M., Virgin, I., and Andersson, B. (1993). Photoinhibition of photosystem II. inactivation, protein damage and turnover. Biochim. Biophys. Acta 1143, 113-134. doi: 10.1016/0005-2728(93)90134-2

Baker, N. R. (1996). "Photoinhibition of Photosynthesis," in Light as an Energy Source and Information Carrier in Plant Physiology. Eds. R. C. Jennings, G. Zucchelli, F. Ghetti and G. Colombetti (Boston, MA: Springer US), 89-97.

Bisby, R. H., Morgan, C. G., Hamblett, I., and Gorman, A. A. (1999). Quenching of singlet oxygen by trolox $c$, ascorbate, and amino acids: effects of ph and temperature. J. Phys. Chem. A. 103, 7454-7459. doi: 10.1021/jp990838c

Buettner, G. R. (1993). The pecking order of free radicals and antioxidants: lipid peroxidation, alpha-tocopherol, and ascorbate. Arch. Biochem. Biophys. 300 (2), 535-543. doi: 10.1006/abbi.1993.1074

Burke, M., Land, E. J., Mcgarvey, D. J., and Truscott, T. G. (2000). Carotenoid triplet state lifetimes. J. Photochem. Photobiol. B. 59, 132-138. doi: 10.1016/ S1011-1344(00)00150-0

Carmody, M., Crisp, P. A., D’alessandro, S., Ganguly, D., Gordon, M., Havaux, M., et al. (2016). Uncoupling high light responses from singlet oxygen retrograde signaling and spatial-temporal systemic acquired acclimation. Plant Physiol. 171, 1734-1749. doi: 10.1104/pp.16.00404

D’alessandro, S., Ksas, B., and Havaux, M. (2018). Decoding beta-cyclocitralmediated retrograde signaling reveals the role of a detoxification response in plant tolerance to photooxidative stress. Plant Cell 30, 2495-2511. doi: 10.1105/ tpc. 18.00578

Davies, M. J. (2004). Reactive species formed on proteins exposed to singlet oxygen. Photochem. Photobiol. Sci. 3, 17-25. doi: 10.1039/b307576c

Demmig-Adams, B., and Adams, W. W.3rd (2000). Harvesting sunlight safely. Nature 403, 371, 373-374. doi: 10.1038/35000315

Dogra, V., Duan, J., Lee, K. P., Lv, S., Liu, R., and Kim, C. (2017). FtsH2-dependent proteolysis of EXECUTER1 is essential in mediating singlet oxygen-triggered retrograde signaling in Arabidopsis thaliana. Front. Plant Sci. 8, 1145. doi: 10.3389/fpls.2017.01145

Dogra, V., Rochaix, J. D., and Kim, C. (2018). Singlet oxygen-triggered chloroplast-to-nucleus retrograde signalling pathways: an emerging perspective. Plant Cell Environ. 41, 1727-1738. doi: 10.1111/pce.13332

Dogra, V., Duan, J., Lee, K. P., and Kim, C. (2019a). Impaired PSII proteostasis triggers a UPR-like response in the var2 mutant of Arabidopsis. J. Exp. Bot. 70, 3075-3088. doi: 10.1093/jxb/erz151

Dogra, V., Li, M., Singh, S., Li, M., and Kim, C. (2019b). Oxidative posttranslational modification of EXECUTER1 is required for singlet oxygen sensing in plastids. Nat. Commun. 10, 2834. doi: 10.1038/s41467-019$10760-6$

\section{FUNDING}

This work was supported by the Strategic Priority Research Program from the Chinese Academy of Sciences (Grant No. XDB27040102). VD acknowledge the President's International Fellowship Initiative (PIFI) postdoctoral fellowship from the Chinese Academy of Sciences (No. 2019PB0066).

\section{ACKNOWLEDGMENTS}

We sincerely acknowledge the contributions made by the scientists in the area of ${ }^{1} \mathrm{O}_{2}$ research, as mentioned in this manuscript. We apologize to the authors whose works could not be cited because of space constraints.

Dreaden Kasson, T. M., Rexroth, S., and Barry, B. A. (2012). Light-induced oxidative stress, n-formylkynurenine, and oxygenic photosynthesis. PloS One 7, e42220. doi: 10.1371/journal.pone.0042220

Duan, J., Lee, K. P., Dogra, V., Zhang, S., Liu, K., Caceres-Moreno, C., et al. (2019). Impaired PSII proteostasis promotes retrograde signaling via salicylic acid. Plant Physiol. 180, 2182-2197. doi: 10.1104/pp.19.00483

Durrant, J. R., Giorgi, L. B., Barber, J., Klug, D. R., and Porter, G. (1990). Characterisation of triplet states in isolated photosystem II reaction centres: Oxygen quenching as a mechanism for photodamage. Biochim. Biophys. Acta (BBA) - Bioenerg. 1017, 167-175. doi: 10.1016/0005-2728(90)90148-W

Edelman, M., and Mattoo, A. K. (2008). D1-protein dynamics in photosystem II: the lingering enigma. Photosynth. Res. 98 (1-3), 609-620. doi: 10.1007/s11120008-9342-x

Edge, R., and Truscott, T. G. (1999). "Carotenoid Radicals and the Interaction of Carotenoids with Active Oxygen Species," in The Photochemistry of Carotenoids. Eds. H. A. Frank, A. J. Young, G. Britton and R. J. Cogdell (Dordrecht: Springer Netherlands), 223-234. doi: 10.1007/0-306-48209-6_12

Farmer, E. E., and Mueller, M. J. (2013). ROS-mediated lipid peroxidation and RES-activated signaling. Annu. Rev. Plant Biol. 64, 429-450. doi: 10.1146/ annurevarplant-050312-120132

Fischer, B. B., Ledford, H. K., Wakao, S., Huang, S. G., Casero, D., Pellegrini, M., et al. (2012). SINGLET OXYGEN RESISTANT 1 links reactive electrophile signaling to singlet oxygen acclimation in Chlamydomonas reinhardtii. Proc. Natl. Acad. Sci. U.S.A. 109, E1302-E1311. doi: 10.1073/pnas.1116843109

Foote, C. S. (1968). Mechanisms of photosensitized oxidation. There are several different types of photosensitized oxidation which may be important in biological systems. Science 162, 963-970. doi: 10.1126/science.162.3857.963

Foote, C. S., and Denny, R. W. (1968). Chemistry of singlet oxygen. VII. Quenching by beta.-carotene. J. Am. Chem. Soc. 90, 6233-6235. doi: 10.1016/ S0040-4039(00)70787-8

Foyer, C. H., and Noctor, G. (2005). Redox homeostasis and antioxidant signaling: a metabolic interface between stress perception and physiological responses. Plant Cell 17, 1866-1875. doi: 10.1105/tpc.105.033589

Foyer, C. H., Neukermans, J., Queval, G., Noctor, G., and Harbinson, J. (2012). Photosynthetic control of electron transport and the regulation of gene expression. J. Exp. Bot. 63, 1637-1661. doi: 10.1093/jxb/ers013

Foyer, C. H. (2018). Reactive oxygen species, oxidative signaling and the regulation of photosynthesis. Environ. Exp. Bot. 154, 134-142. doi: 10.1016/ j.envexpbot.2018.05.003

Fufezan, C., Rutherford, A. W., and Krieger-Liszkay, A. (2002). Singlet oxygen production in herbicide-treated photosystem II. FEBS Lett. 532, 407-410. doi: 10.1016/S0014-5793(02)03724-9

Gobel, C., Feussner, I., Hamberg, M., and Rosahl, S. (2002). Oxylipin profiling in pathogen-infected potato leaves. Biochim. Biophys. Acta 1584, 55-64. doi: 10.1016/S1388-1981(02)00268-8

Gollnick, K. (1968). “Type II Photosensitized Oxygenation Reactions,” in Oxidation of Organic Compounds. (American Chemical Society) 78-101. doi: 10.1021/ba-1968-0077.ch067 
Gorman, A. A., and Rodgers, M.a.J. (1992). Current perspectives of singlet oxygen detection in biological environments. J. Photochem. Photobiol. B. 14, 159-176. doi: 10.1016/1011-1344(92)85095-C

Hakala, M., Tuominen, I., Keranen, M., Tyystjarvi, T., and Tyystjarvi, E. (2005). Evidence for the role of the oxygen-evolving manganese complex in photoinhibition of Photosystem II. Biochim. Biophys. Acta 1706, 68-80. doi: 10.1016/j.bbabio.2004.09.001

Hideg, E., Kalai, T., Hideg, K., and Vass, I. (1998). Photoinhibition of photosynthesis in vivo results in singlet oxygen production detection via nitroxide-induced fluorescence quenching in broad bean leaves. Biochemistry 37, 11405-11411. doi: 10.1021/bi972890+

Hideg, E. (2004). Detection of free radicals and reactive oxygen species. Methods Mol. Biol. 274, 249-260. doi: 10.1385/1-59259-799-8:249

Imbusch, R., and Mueller, M. J. (2000). Formation of isoprostane F(2)-like compounds (phytoprostanes $\mathrm{F}(1)$ ) from alpha-linolenic acid in plants. Free Radic. Biol. Med. 28, 720-726. doi: 10.1104/pp.109.146589

Jansen, M. A., Mattoo, A. K., and Edelman, M. (1999). D1-D2 protein degradation in the chloroplast. complex light saturation kinetics. Eur. J. Biochem. 260, 527532. doi: 10.1046/j.1432-1327.1999.00196.x

Kato, Y., and Sakamoto, W. (2009). Protein quality control in chloroplasts: a current model of D1 protein degradation in the photosystem II repair cycle. J. Biochem. 146, 463-469. doi: 10.1093/jb/mvp073

Kato, Y., Miura, E., Ido, K., Ifuku, K., and Sakamoto, W. (2009). The variegated mutants lacking chloroplastic FtsHs are defective in D1 degradation and accumulate reactive oxygen species. Plant Physiol. 151, 1790-1801. doi: 10.1104/pp.109.146589

Keren, N., Berg, A., Van Kan, P. J., Levanon, H., and Ohad, I. (1997). Mechanism of photosystem II photoinactivation and D1 protein degradation at low light: the role of back electron flow. Proc. Natl. Acad. Sci. U.S.A. 94, 1579-1584. doi: 10.1073/pnas.94.4.1579

Kim, C., and Apel, K. (2013). Singlet oxygen-mediated signaling in plants: moving from flu to wild type reveals an increasing complexity. Photosynth. Res. 116, 455-464. doi: 10.1007/s11120-013-9876-4

Kim, C., Meskauskiene, R., Apel, K., and Laloi, C. (2008). No single way to understand singlet oxygen signalling in plants. EMBO Rep. 9, 435-439. doi: 10.1038/embor.2008.57

Kim, C., Meskauskiene, R., Zhang, S., Lee, K. P., Lakshmanan Ashok, M., Blajecka, K., et al. (2012). Chloroplasts of Arabidopsis are the source and a primary target of a plant-specific programmed cell death signaling pathway. Plant Cell 24, 3026-3039. doi: $10.1105 /$ tpc.112.100479

Koivuniemi, A., Aro, E. M., and Andersson, B. (1995). Degradation of the D1- and D2-proteins of photosystem II in higher plants is regulated by reversible phosphorylation. Biochemistry 34, 16022-16029. doi: 10.1021/bi00049a016

Krieger-Liszkay, A. (2005). Singlet oxygen production in photosynthesis. J. Exp. Bot. 56, 337-346. doi: 10.1093/jxb/erh237

Krieger-Liszkay, A., and Trebst, A. (2006). Tocopherol is the scavenger of singlet oxygen produced by the triplet states of chlorophyll in the PSII reaction centre. J. Exp. Bot. 57, 1677-1684. doi: 10.1093/jxb/erl002

Krieger-Liszkay, A., Fufezan, C., and Trebst, A. (2008). Singlet oxygen production in photosystem II and related protection mechanism. Photosynth. Res. 98, 551564. doi: $10.1007 / \mathrm{s} 11120-008-9349-3$

Kruk, J., and Trebst, A. (2008). Plastoquinol as a singlet oxygen scavenger in photosystem II. Biochim. Biophys. Acta 1777, 154-162. doi: 10.1016/ j.bbabio.2007.10.008

Kruk, J., Hollander-Czytko, H., Oettmeier, W., and Trebst, A. (2005). Tocopherol as singlet oxygen scavenger in photosystem II. J. Plant Physiol. 162, 749-757. doi: 10.1016/j.jplph.2005.04.020

Ledford, H. K., Chin, B. L., and Niyogi, K. K. (2007). Acclimation to singlet oxygen stress in Chlamydomonas reinhardtii. Eukaryot. Cell 6, 919-930. doi: 10.1128/ EC.00207-06

Lee, K. P., Kim, C., Landgraf, F., and Apel, K. (2007). EXECUTER1- and EXECUTER2-dependent transfer of stress-related signals from the plastid to the nucleus of Arabidopsis thaliana. Proc. Natl. Acad. Sci. U.S.A. 104, 1027010275. doi: 10.1073/pnas.0702061104

Li, Z., Wakao, S., Fischer, B. B., and Niyogi, K. K. (2009). Sensing and responding to excess light. Annu. Rev. Plant Biol. 60, 239-260. doi: 10.1146/ annurev.arplant.58.032806.103844

Malnoë, A., Wang, F., Girard-Bascou, J., Wollman, F.-A., and De Vitry, C. (2014). Thylakoid FtsH protease contributes to photosystem II and cytochrome b6f remodeling in chlamydomonas reinhardtii under stress conditions. Plant Cell 26, 373-390. doi: 10.1105/tpc.113.120113

Mano, J., Miyatake, F., Hiraoka, E., and Tamoi, M. (2009). Evaluation of the toxicity of stress-related aldehydes to photosynthesis in chloroplasts. Planta 230, 639-648. doi: 10.1007/s00425-009-0964-9

Mano, J. I., Tokushige, K., Mizoguchi, H., Fujii, H., and Khorobrykh, S. (2010). Accumulation of lipid peroxide-derived, toxic .ALPHA.,.BETA.-unsaturated aldehydes (E)-2-pentenal, acrolein and (E)-2-hexenal in leaves under photoinhibitory illumination. Plant Biotechnol. 27, 193-197. doi: 10.5511/ plantbiotechnology.27.193

Mano, J. (2012). Reactive carbonyl species: their production from lipid peroxides, action in environmental stress, and the detoxification mechanism. Plant Physiol. Biochem. 59, 90-97. doi: 10.1016/j.plaphy.2012.03.010

Meskauskiene, R., Nater, M., Goslings, D., Kessler, F., Op Den Camp, R., and Apel, K. (2001). FLU: a negative regulator of chlorophyll biosynthesis in Arabidopsis thaliana. Proc. Natl. Acad. Sci. U.S.A. 98, 12826-12831. doi: 10.1073/ pnas. 221252798

Metz, J. G., Pakrasi, H. B., Seibert, M., and Arntzer, C. J. (1986). Evidence for a dual function of the herbicide-binding D1 protein in photosystem II. FEBS Lett. 205, 269-274. doi: 10.1016/0014-5793(86)80911-5

Michaeli, A., and Feitelson, J. (1994). Reactivity of singlet oxygen toward amino acids and peptides. Photochem. Photobiol. 59, 284-289. doi: 10.1111/j.17511097.1994.tb05035.x

Mueller, M. J., Mene-Saffrane, L., Grun, C., Karg, K., and Farmer, E. E. (2006). Oxylipin analysis methods. Plant J. 45, 472-489. doi: 10.1111/j.1365313X.2005.02614.x

Mueller, S., Hilbert, B., Dueckershoff, K., Roitsch, T., Krischke, M., Mueller, M. J., et al. (2008). General detoxification and stress responses are mediated by oxidized lipids through TGA transcription factors in Arabidopsis. Plant Cell 20, 768-785. doi: 10.1105/tpc.107.054809

Muller, P., Li, X. P., and Niyogi, K. K. (2001). Non-photochemical quenching. A response to excess light energy. Plant Physiol. 125, 1558-1566. doi: 10.1104/ pp.125.4.1558

Nishiyama, Y., and Murata, N. (2014). Revised scheme for the mechanism of photoinhibition and its application to enhance the abiotic stress tolerance of the photosynthetic machinery. Appl. Microbiol. Biotechnol. 98, 8777-8796. doi: 10.1007/s00253-014-6020-0

Nishiyama, Y., Allakhverdiev, S. I., Yamamoto, H., Hayashi, H., and Murata, N. (2004). Singlet oxygen inhibits the repair of photosystem II by suppressing the translation elongation of the D1 protein in Synechocystis sp. PCC 6803. Biochemistry 43, 11321-11330. doi: 10.1021/bi036178q

Nishiyama, Y., Allakhverdiev, S. I., and Murata, N. (2006). A new paradigm for the action of reactive oxygen species in the photoinhibition of photosystem II. Biochim. Biophys. Acta 1757, 742-749. doi: 10.1016/j.bbabio.2006.05.013

Op Den Camp, R. G., Przybyla, D., Ochsenbein, C., Laloi, C., Kim, C., Danon, A., et al. (2003). Rapid induction of distinct stress responses after the release of singlet oxygen in Arabidopsis. Plant Cell 15, 2320-2332. doi: 10.1105/ tpc. 014662

Przybyla, D., Gobel, C., Imboden, A., Hamberg, M., Feussner, I., and Apel, K. (2008). Enzymatic, but not non-enzymatic, 1O2-mediated peroxidation of polyunsaturated fatty acids forms part of the EXECUTER1-dependent stress response program in the flu mutant of Arabidopsis thaliana. Plant J. 54, 236248. doi: 10.1111/j.1365-313X.2008.03409.x

Ramel, F., Birtic, S., Cuiné, S., Triantaphylidès, C., Ravanat, J.-L., and Havaux, M. (2012a). Chemical quenching of singlet oxygen by carotenoids in plants. Plant Physiol. 158, 1267-1278. doi: 10.1104/pp.111.182394

Ramel, F., Birtic, S., Ginies, C., Soubigou-Taconnat, L., Triantaphylides, C., and Havaux, M. (2012b). Carotenoid oxidation products are stress signals that mediate gene responses to singlet oxygen in plants. Proc. Natl. Acad. Sci. U.S.A. 109, 5535-5540. doi: 10.1073/pnas.1115982109

Ramel, F., Ksas, B., Akkari, E., Mialoundama, A. S., Monnet, F., Krieger-Liszkay, A., et al. (2013). Light-induced acclimation of the Arabidopsis chlorinal mutant to singlet oxygen. Plant Cell 25, 1445-1462. doi: 10.1105/tpc.113.109827

Ravanat, J. L., Di Mascio, P., Martinez, G. R., Medeiros, M. H., and Cadet, J. (2000). Singlet oxygen induces oxidation of cellular DNA. J. Biol. Chem. 275, 40601-40604. doi: 10.1074/jbc.M006681200

Rinalducci, S., Pedersen, J. Z., and Zolla, L. (2004). Formation of radicals from singlet oxygen produced during photoinhibition of isolated light-harvesting 
proteins of photosystem II. Biochim. Biophys. Acta 1608, 63-73. doi: 10.1016/ j.bbabio.2003.10.009

Roach, T., Baur, T., Stoggl, W., and Krieger-Liszkay, A. (2017). Chlamydomonas reinhardtii responding to high light: a role for 2-propenal (acrolein). Physiol. Plant 161, 75-87. doi: 10.1111/ppl.12567

Roach, T., Stoggl, W., Baur, T., and Kranner, I. (2018). Distress and eustress of reactive electrophiles and relevance to light stress acclimation via stimulation of thiol/disulphide-based redox defences. Free Radic. Biol. Med. 122, 65-73. doi: 10.1016/j.freeradbiomed.2018.03.030

Rochaix, J. D. (2011). Regulation of photosynthetic electron transport. Biochim. Biophys. Acta 1807, 375-383. doi: 10.1016/j.bbabio.2010.11.010

Santabarbara, S., Cazzalini, I., Rivadossi, A., Garlaschi, F. M., Zucchelli, G., and Jennings, R. C. (2002). Photoinhibition in vivo and in vitro involves weakly coupled chlorophyll-protein complexes. Photochem. Photobiol. 75, 613-618. doi: 10.1562/0031-8655(2002)075<0613:PIVAIV>2.0.CO;2

Santabarbara, S., Agostini, G., Casazza, A. P., Syme, C. D., Heathcote, P., Böhles, F., et al. (2007). Chlorophyll triplet states associated with Photosystem I and Photosystem II in thylakoids of the green alga Chlamydomonas reinhardtii. Biochim. Biophys. Acta (BBA) - Bioenerg. 1767, 88-105. doi: 10.1016/ j.bbabio.2006.10.007

Sattler, S. E., Mene-Saffrane, L., Farmer, E. E., Krischke, M., Mueller, M. J., and Dellapenna, D. (2006). Nonenzymatic lipid peroxidation reprograms gene expression and activates defense markers in Arabidopsis tocopherol-deficient mutants. Plant Cell 18, 3706-3720. doi: 10.1105/tpc.106.044065

Shao, N., Duan, G. Y., and Bock, R. (2013). A mediator of singlet oxygen responses in Chlamydomonas reinhardtii and Arabidopsis identified by a luciferase-based genetic screen in algal cells. Plant Cell 25, 4209-4226. doi: 10.1105/ tpc.113.117390

Shumbe, L., Bott, R., and Havaux, M. (2014). Dihydroactinidiolide, a high lightinduced beta-carotene derivative that can regulate gene expression and photoacclimation in Arabidopsis. Mol. Plant 7, 1248-1251. doi: 10.1093/mp/ ssu028

Shumbe, L., D’alessandro, S., Shao, N., Chevalier, A., Ksas, B., Bock, R., et al. (2017). METHYLENE BLUE SENSITIVITY 1 (MBS1) is required for acclimation of Arabidopsis to singlet oxygen and acts downstream of betacyclocitral. Plant Cell Environ. 40, 216-226. doi: 10.1111/pce.12856

Szilard, A., Sass, L., Hideg, E., and Vass, I. (2005). Photoinactivation of photosystem II by flashing light. Photosynth. Res. 84, 15-20. doi: 10.1007/ s11120-004-7161-2

Takahashi, S., and Murata, N. (2008). How do environmental stresses accelerate photoinhibition? Trends Plant Sci. 13, 178-182. doi: 10.1016/ j.tplants.2008.01.005

Telfer, A., Dhami, S., Bishop, S. M., Phillips, D., and Barber, J. (1994). betaCarotene quenches singlet oxygen formed by isolated photosystem II reaction centers. Biochemistry 33, 14469-14474. doi: 10.1021/bi00252a013

Telfer, A. (2002). What is beta-carotene doing in the photosystem II reaction centre? Philos. Trans. R. Soc. Lond. B. Biol. Sci. 357, 1431-1439; discussion 1439-1440, 1469-1470. doi: 10.1098/rstb.2002.1139
Triantaphylides, C., and Havaux, M. (2009). Singlet oxygen in plants: production, detoxification and signaling. Trends Plant Sci. 14, 219-228. doi: 10.1016/ j.tplants.2009.01.008

Van Mieghem, F., Brettel, K., Hillman, B., Kamlowski, A., Rutherford, A. W., and Schlodder, E. (1995). Charge recombination reactions in photosystem ii. 1. yields, recombination pathways, and kinetics of the primary pair. Biochemistry 34, 4798-4813. doi: 10.1021/bi00014a038

Vass, I., and Cser, K. (2009). Janus-faced charge recombinations in photosystem II photoinhibition. Trends Plant Sci. 14, 200-205. doi: 10.1016/ j.tplants.2009.01.009

Vass, I., Styring, S., Hundal, T., Koivuniemi, A., Aro, E., and Andersson, B. (1992). Reversible and irreversible intermediates during photoinhibition of photosystem II: stable reduced QA species promote chlorophyll triplet formation. Proc. Natl. Acad. Sci. U.S.A. 89, 1408-1412. doi: 10.1073/ pnas.89.4.1408

Wagner, D., Przybyla, D., Op Den Camp, R., Kim, C., Landgraf, F., Lee, K. P., et al. (2004). The genetic basis of singlet oxygen-induced stress responses of Arabidopsis thaliana. Science 306, 1183-1185. doi: 10.1126/science.1103178

Wang, L., Kim, C., Xu, X., Piskurewicz, U., Dogra, V., Singh, S., et al. (2016). Singlet oxygen- and EXECUTER1-mediated signaling is initiated in grana margins and depends on the protease FtsH2. Proc. Natl. Acad. Sci. U.S.A. 113, E3792-E3800. doi: 10.1073/pnas.1603562113

Watabe, N., Ishida, Y., Ochiai, A., Tokuoka, Y., and Kawashima, N. (2007). Oxidation decomposition of unsaturated fatty acids by singlet oxygen in phospholipid bilayer membranes. J. Oleo. Sci. 56, 73-80. doi: 10.5650/jos.56.73

Weber, H., Chetelat, A., Reymond, P., and Farmer, E. E. (2004). Selective and powerful stress gene expression in Arabidopsis in response to malondialdehyde. Plant J. 37, 877-888. doi: 10.1111/j.1365-313x.2003.02013.x

Yadav, D. K., Kruk, J., Sinha, R. K., and Pospisil, P. (2010). Singlet oxygen scavenging activity of plastoquinol in photosystem II of higher plants: electron paramagnetic resonance spin-trapping study. Biochim. Biophys. Acta 1797, 1807-1811. doi: 10.1016/j.bbabio.2010.07.003

Zhang, S., Apel, K., and Kim, C. (2014). Singlet oxygen-mediated and EXECUTER-dependent signalling and acclimation of Arabidopsis thaliana exposed to light stress. Philos. Trans. R. Soc. Lond. B. Biol. Sci. 369, 20130227.

Zhu, J. K. (2016). Abiotic stress signaling and responses in plants. Cell 167, 313-324. doi: 10.1016/j.cell.2016.08.029

Conflict of Interest: The authors declare that the research was conducted in the absence of any commercial or financial relationships that could be construed as a potential conflict of interest.

Copyright (c) 2020 Dogra and Kim. This is an open-access article distributed under the terms of the Creative Commons Attribution License (CC BY). The use, distribution or reproduction in other forums is permitted, provided the original author(s) and the copyright owner(s) are credited and that the original publication in this journal is cited, in accordance with accepted academic practice. No use, distribution or reproduction is permitted which does not comply with these terms. 